\title{
A constitutive model for hydromechanically coupled behavior of unsaturated soils with hydraulic hysteresis
}

\author{
Mustafa Mert Eyüpgiller ${ }^{1}$, Melih Birhan Kenanoğlu², Mehmet Barış Can Ülker, ${ }^{1,}$, and Nabi Kartal Toker ${ }^{2}$ \\ ${ }^{1}$ Istanbul Technical University, Disaster Management Institute, 34469 Istanbul, Turkey \\ ${ }^{2}$ Middle East Technical University, Civil Engineering Department, 06800 Ankara, Turkey
}

\begin{abstract}
There are several constitutive models developed for understanding coupled hydromechanical behavior of three phase medium of unsaturated soils as well as models for explaining hydraulic hysteresis in water retention. However, very few attempts that merge the two aspects of behavior are available. This study develops a one-way coupled model for understanding the hydromechanical behavior of unsaturated soils. In addition to the hysteresis between main drying and wetting retention curves, the model considers non-uniqueness of retention behavior resulting from void ratio changes due to compression under the stress application. As for the elastoplastic stress strain relationship of soil skeleton, the model is based on the formulation of classical plasticity relying on the critical state concept. Consequently, volumetric deformation due to wetting-drying cycles and its effect on elastoplastic behavior through simultaneously changing matric suction is modeled. Model results are calibrated with the results of isotropic compression stages of triaxial tests at both constant suction and constant water content conditions.
\end{abstract}

\section{Introduction}

While there have been many unsaturated soil models since the pioneering elasto-plastic constitutive model called Barcelona Basic Model (BBM) by Alonso et al. (1990) [1] more studies are required to fully understand the hydromechanical coupling of unsaturated soil. The popularity of BBM, which makes use of net stress and suction as independent stress state variables, has increasingly grown over the last three decades. Various features of unsaturated soil behavior such as suction hardening or collapse upon wetting are further captured within the elasto-plastic framework of BBM (Gens 2010 [2]). Modifications on the BBM are proposed by many other researchers also (Wheeler \& Sivakumar 1995 [3]; Cui \& Delage 1996 [4]; Sanchez et al. 2005 [5]). However, BBM and other models that follow BBM have certain shortcomings on the modeling of coupled hydromechanical behavior of unsaturated soil.

Incorporation of soil water retention behavior into a theoretical basis of an unsaturated soil model is essential in constitutive modeling of hydromechanical coupling (Tarantino 2009 [6], Gallipoli et al. 2015 [7]). Thus, it is necessary to understand the characteristic soil water retention behavior which is hysteretic in nature and which depends on drying and wetting regimes where soil may have different suction values with the same amount of water. Experimental studies show that scanning curves emerge inside boundary retention curves (Lins et al. 2007 [8]; Miller et al. 2008 [9]; Lu \& Khorshidi 2015 [10]). Therefore any irreversible unsaturated soil behavior between suction and degree of saturation resulting from such a hysteretic behavior should be considered in developing a coupled hydromechanical model.

In this study, a one-way coupled model for understanding the hydromechanical behavior of unsaturated soils is developed. In addition to the hysteresis between main drying and wetting curves, the model considers non-uniqueness of retention behavior resulting from void ratio changes due to compression under net mean stress. For the elastoplastic stress-strain relationship of the soil skeleton, the model is mechanically based on critical state concept. Model results are calibrated with the results of isotropic compression stages of triaxial tests at both constant suction and constant water content conditions.

\section{Hydromechanical coupling}

\subsection{Mathematical formulation}

The mathematical formulation of the model is developed such that stress-strain relationship is based upon the BBM, which adapts the Modified Cam-Clay model (MCC) using the critical state concept. Independent stress state variables used in BBM, namely the net stress and suction, are employed by the model. According to the model, changes in void ratio are related independently to the increments of net mean stress and suction as below:

\footnotetext{
* Corresponding author: mbulker@itu.edu.tr
} 


$$
\begin{gathered}
d v=-\kappa \frac{d p}{p} \\
d v=-\kappa \frac{d s}{s+p_{a t m}}
\end{gathered}
$$

Equations above are the basic elastic constitutive relations of BBM written in terms of the changes in specific volume, $\mathrm{dv}$, net mean stress, $d p$, suction, $d s$, and also the elastic constants, $\kappa, \kappa_{s}$ and the reference pressure of $1 \mathrm{~atm}, p_{\text {atm }}$. Even though the stress state include independent relations, the yield surface of BBM (which is essentially the yield surface of MCC for fully saturated soil) is a function of suction. Any suction increase results in an expansion of the elastic region within the yield surface (Fig. 1). In Fig. 1, the preconsolidation pressure, $p_{0}$, which is used as the hardening parameter in the model, increases with suction and an asterisk indicates a fully saturated state. The lowest net mean stress value of the elastic region, $p_{s}$, is linearly related to suction.

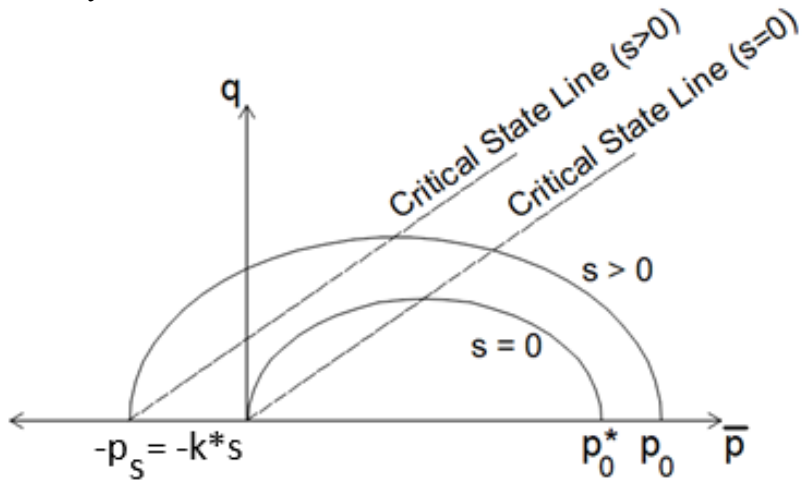

Fig. 1. Dependence of the yield surface on suction.

Total void ratio consisting of both a mechanical part dictated by mean net stress and a hydraulic part controlled by suction, hence subscripts, $m$ and $s$, is written as below:

$$
d v=d v_{s}+d v_{m}=\kappa \frac{d p}{p}-\kappa \frac{d s}{s+p_{a t m}}
$$

Here, coefficients ( $\kappa$ and $\kappa_{s}$ ) are replaced with $\lambda$ and $\lambda_{s}$ depending on whether the stress vector is on elastic loading (or elastic unloading) or plastic loading stages, respectively. Equations given above cover mainly the change caused by mechanical interactions. The formulation of the model in terms of changes caused by hydraulic behavior is obtained in terms of two independent state variables, namely the degree of saturation $S_{r}$ and porosity $n$. The following intrinsic equation is expanded by chain rule as:

$$
\begin{gathered}
\theta=S_{r} n \\
d \theta=S_{r} d n+n d S_{r}
\end{gathered}
$$

$$
d S_{r}=\left(\frac{1}{n} \frac{d \theta}{d \varepsilon_{v p}}-\frac{\theta}{n^{2}} \frac{d n}{d \varepsilon_{v p}}\right) \frac{d \varepsilon_{v p}}{d p} d p+\underbrace{\left(\frac{1}{n} \frac{d \theta}{d s}-\frac{\theta}{n^{2}} \frac{d n}{d s}\right)}_{\left(d S_{r} / d s\right)_{\text {SWRC }}} d s
$$

Multiplier of the suction increment, ds, can be obtained from the soil-water retention curve (SWRC), thus, the second parenthesis in the above form yields the derivative of the SWRC with respect to suction for a given suction value. Although any retention curve model can be implemented in this formulation, van Genuchten (1980) [11] retention behavior is used in this study. Rearranging the terms yields:

$d S_{r}=\left(-\frac{\lambda}{e} \frac{1}{p} \frac{d \theta}{d \varepsilon_{v p}}+\frac{\theta}{e^{2}} \frac{\lambda}{p}\right) d p+\left(\frac{d S_{r}}{d s}\right)_{S W R C} d s$

where $\theta$ is the volumetric water content and $\varepsilon_{v p}$ is the plastic volumetric strain. The term, $d \theta /\left(d \varepsilon_{v p}\right)$, cannot be derived from the intrinsic relations, therefore, experimental results are necessary quantify this term.

\subsection{Incorporation of hydraulic hysteresis}

Hysteretic water retention behavior of unsaturated soil is captured assuming main drying and main wetting curves bounding all possible values following the regime reversals. Two separate formulae (one for drying and another for wetting) are developed for modeling of scanning soil-water retention curves. Formulae are developed by interpolating a power of volumetric water content ratios over the ratios of logarithms of suction, devised from the observations of experimental data (Kenanoğlu \& Toker 2018 [12]).

$$
\frac{A}{B}=\frac{C}{D}\left(\frac{E}{F}\right)^{K}
$$

where all variables are illustrated in Fig. 2 .

For each point on the scanning curve, the suction values on the main drying and main wetting SWRC corresponding to consecutive water contents are determined. The unknown suction value for current water content should lie in between these suction values and following relations are devised accordingly.

The equations of the scanning curve in the direction of wetting and drying are respectively given in the following equations:

$$
\begin{gathered}
\log \left(s_{j}\right)=\log \left(s_{j}^{w}\right)+\frac{\log \left(\frac{s_{j-1}}{s_{j-1}^{w}}\right)}{\log \left(\frac{s_{j-1}^{d}}{s_{j-1}^{w}}\right)}\left(\frac{\theta_{m}-\theta_{j}}{\theta_{m}-\theta_{j-1}}\right)^{K} \log \left(\frac{s_{j}^{d}}{s_{j}^{w}}\right) \\
\log \left(s_{j}\right)=\log \left(s_{j}^{d}\right)-\frac{\log \left(\frac{s_{j-1}^{d}}{s_{j-1}}\right)}{\log \left(\frac{s_{j-1}^{d}}{s_{j-1}^{w}}\right)}\left(\frac{\theta_{j}-\theta_{r}}{\theta_{j-1}-\theta_{r}}\right)^{K} \log \left(\frac{s_{j}^{d}}{s_{j}^{w}}\right)
\end{gathered}
$$


where $\log \left(s_{j}\right)$ is the logarithm of the presently unknown suction value, $\log \left(s_{j}^{w}\right)$ is the logarithm of corresponding value of suction on the main wetting curve for $\theta_{j}, s_{j-1}$ is the value of suction at previous time step, $s_{j-1}^{w}$ is the corresponding value of suction on the main wetting curve for $\theta_{j-1}, s^{d}{ }_{j-1}$ is the corresponding value of suction on the main drying curve for $\theta_{j-1}, \theta_{s}$ is the saturated water content, $\theta_{m}$ is the maximum water content on main wetting curve, $\theta_{r}$ is the residual water content, $\theta_{j}$ is the water content at present condition, $\theta_{j-1}$ is the water content at previous condition, $s^{d}$ is the corresponding value of suction on the main drying curve for $\theta_{j}, s_{j}^{w}$ is the corresponding value of suction on main wetting curve for $\theta_{j}$ and $K$ is the power-type parameter, which controls the curvature of the scanning curve. It should be noted that main drying and main wetting curves can be in the form of any retention curve equation such as van Genuchten (1980) [11]. As an example, proposed equations are used to trace the experimental data of a scanning loop in Fig. 3.
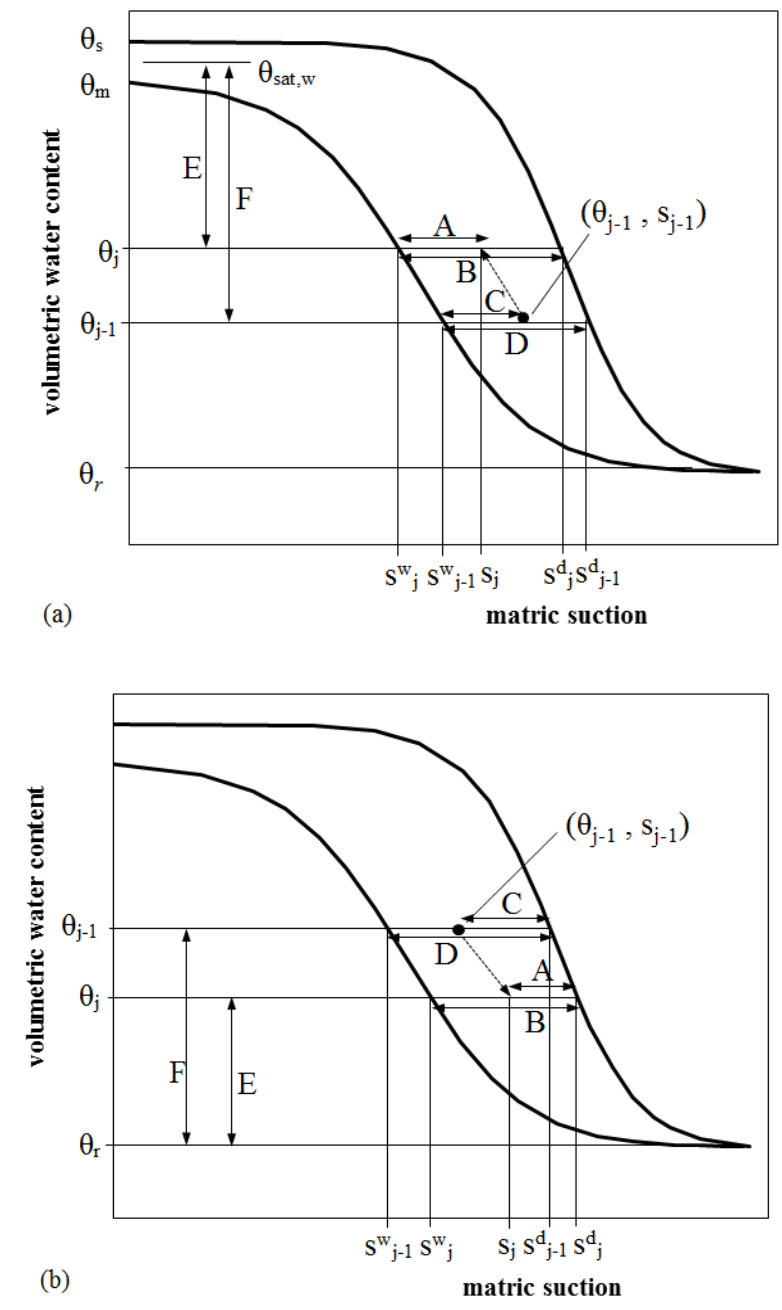

Fig. 2. Sketch of variables given in the general form of (8), a) wetting scanning curve, b) drying scanning curve.

An empirical equation is proposed for quantifying the power parameter $K$ using a variable termed as fractional water content $\left(\Theta_{f}\right)$. In the wetting regime, $\Theta_{f}$ is similar to widely used effective volumetric water content, $\Theta$, except that $\theta_{m}$ replaces the saturated water content $\left(\theta_{s}\right)$. In the drying regime, $\Theta_{f}$ is equal to $(1-\Theta)$.

$$
\begin{gathered}
\Theta_{f}=\frac{\theta_{j-1}-\theta_{r}}{\theta_{m}-\theta_{r}} \\
\Theta_{f}=1-\Theta=\frac{\theta_{s}-\theta_{j-1}}{\theta_{s}-\theta_{r}}
\end{gathered}
$$

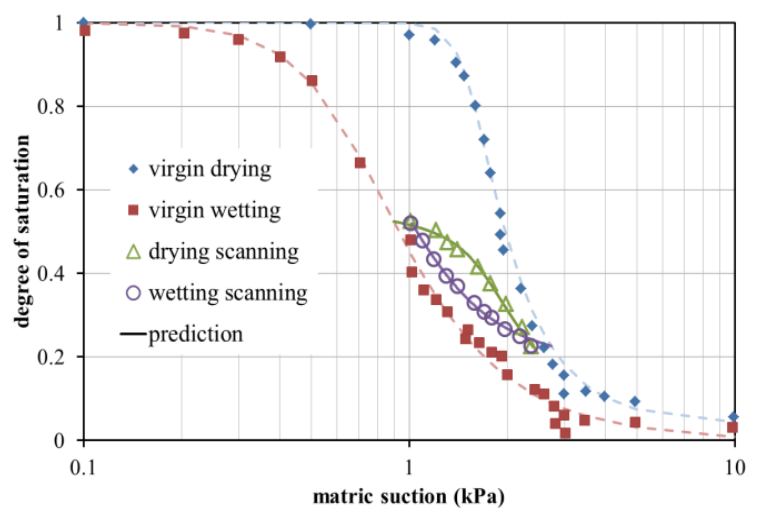

Fig. 3. The proposed hysteresis model for a scanning loop (experimental data from Lins et al. 2007 [8]).

Data collected from the literature are processed and the relationship between fractional water content values at the initial state and power parameter is investigated (Fig.4). Number of data is extended by processing successive experimental data points on scanning curve. A mathematical expression is fitted to experimental data given in Fig. 4 using the least squares method leading to an empirical relationship that seems to be close to $2 / \Theta_{f}$ :

$$
K=2.002 \times \Theta_{f}^{-0.999} \approx 2 / \Theta_{f}
$$

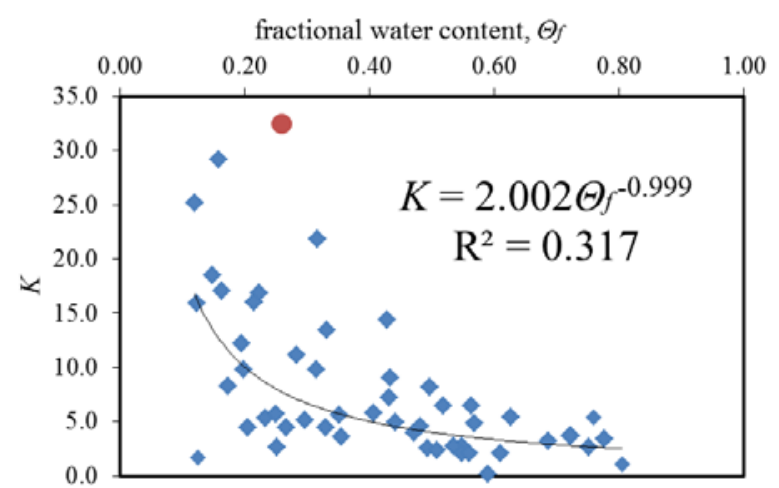

Fig. 4. Relationship between fractional water content and power parameter for data available in the literature (expanded from Kenanoğlu \& Toker 2018 [12]).

The low value for coefficient of correlation $\mathrm{R}^{2}$ seems to indicate poor correlation in experimental data; however, the sensitivity of scanning curve on higher values of power parameter is quite low. For example, the prediction of equation (13) for the furthest outlier (red data point in Fig. 4), is not too far from the least square fit to the experimental data using equation (10). 


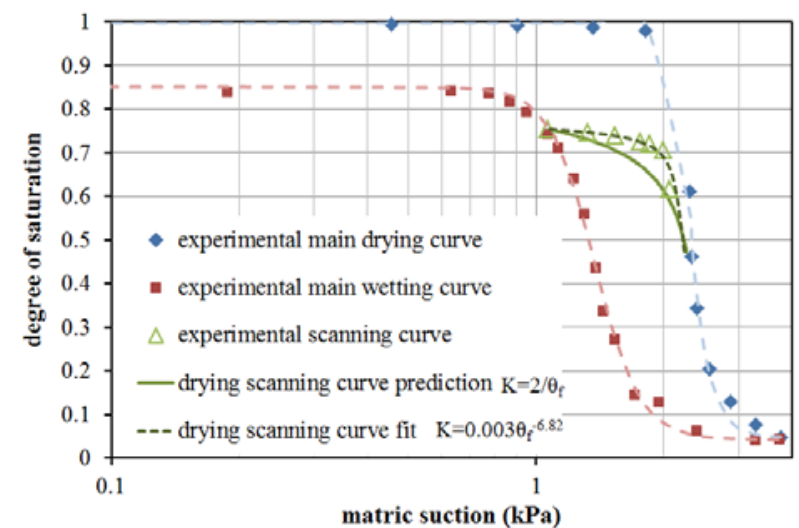

Fig. 5. Comparison of the proposed emprical equation (13) to experimental data of drying scanning curve from Mohamed and Sharma (2007) [13], which is the farthest outlier (red colored data point in Fig. 4), therefore, the worst performance of the prediction.

Proposed relations are presented in the form that can predict any suction increment from the given increment of water content which is then predicted from an iterative solution of either (14) or (15). Following equations are used for the wetting and drying regimes, respectively:

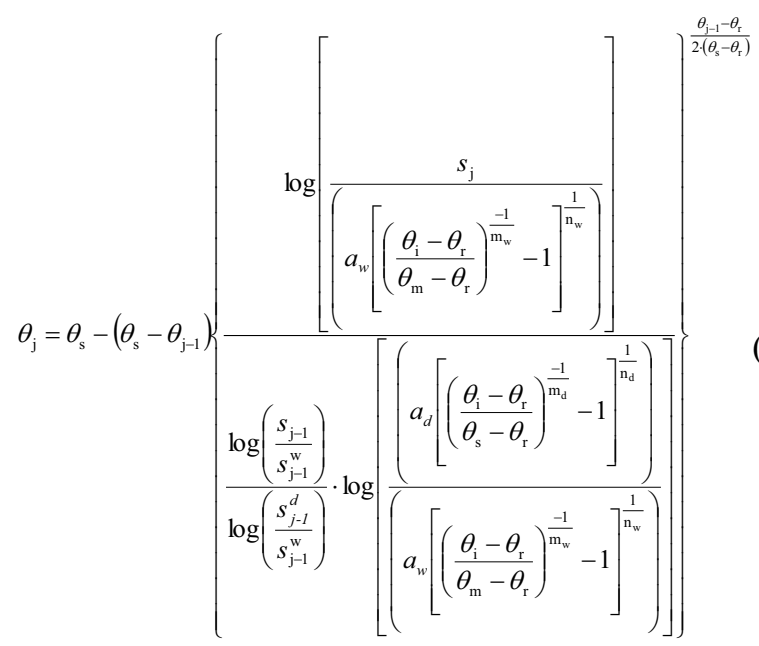

and for drying regime;

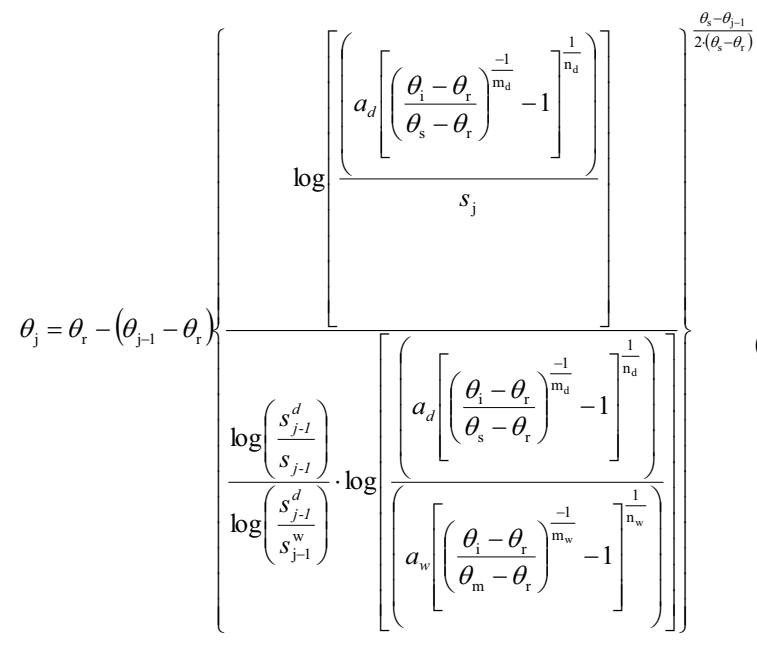

where $a_{w}, m_{w}, n_{w}, a_{d}, m_{d}$ and $n_{d}$ are fitting parameters of van Genuchten (1980) [11] for main wetting curve and main drying curve, $\theta_{i}$ is iteration parameter and it can be taken equal to $\theta_{j-1}$ at the initial step of iteration. It should be noted that any form of retention curve equation could be implemented into (14) and (15) instead of van Genuchten (1980) [11].

\section{Model validation}

The proposed model is validated through simulating the compression stages of a number of unsaturated triaxial experiments. Data from three experimental studies are used for this purpose, two of these are to validate the accuracy of coupled response of the model, and the last one is to verify that proposed scanning curve functions provide the hydraulic hysteresis required to model cyclic changes in suction.

The model requires the BBM parameters as well as the SWRC of soil. The parameters for BBM and retention curve used for each of the three subject soils are given in Table 1 .

Table 1. Model parameters used in Mersin silt simulation

\begin{tabular}{c|c|c|c}
\hline parameters & (Fig. 6 to 8) & (Fig. 9 to 10) & (Fig. 11) \\
\hline$\lambda$ & 0.086 & $0.047,0.040,0.039$ & 0.13 \\
$\kappa$ & 0.0321 & $0.015,0.011,0.010$ & 0.02 \\
$\kappa_{\mathrm{s}}$ & 0.008 & 0.008 & 0.03 \\
$\mathrm{k}$ & 0.4 & 0.4 & 0.5 \\
$\mathrm{p}_{0}(\mathrm{kPa})$ & 90 & $160,235,244$ & 15 \\
$\mathrm{v}$ & 1.83 & $1.95,1.93,1.92$ & 2.153 \\
vG_m & 0.018 & 0.018 & 0.06 \\
vG_n & 60 & 40 & 2.8 \\
vG_ $\mathrm{a}_{\mathrm{d}}$ & 20 & 58 & 100 \\
vG_m & 0.022 & 0.0252 & 10 \\
vG_n & 45 & 40 & 2 \\
vG_a & 9 & 25 & 15 \\
\hline
\end{tabular}

For Mersin silt, data from a consolidated-drained (CD) triaxial test under constant suction are used to calibrate the fitting parameters. As presented in the mathematical formulation, suction increment is incorporated into the SWRC. van Genuchten (1980) [11]

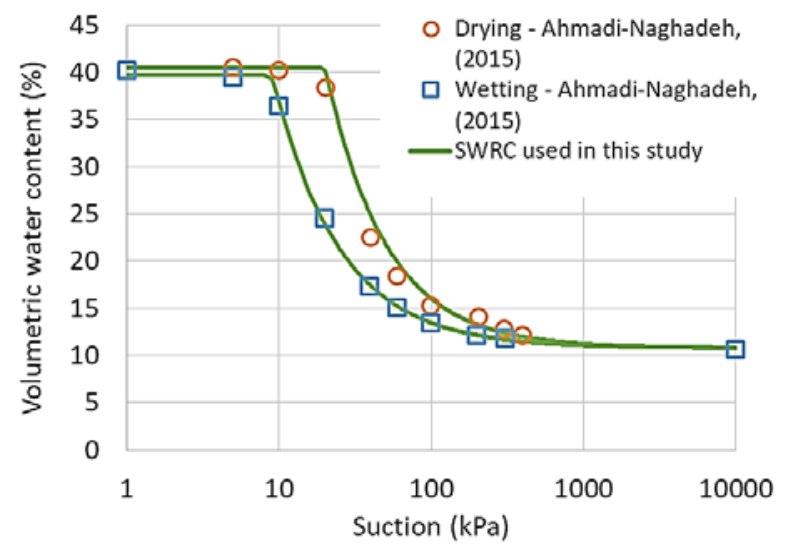

Fig. 6. The SWRC of the Mersin Silt. 
equation is used to obtain a continuous function for the discrete SWRC data given in the study of AhmadiNaghadeh (2015) [14] (Fig. 6). The triaxial CD test conducted in this study includes a suction equilibrium stage (at constant net mean stress of $10 \mathrm{kPa}$ ) and an isotropic loading stage (at constant suction of $100 \mathrm{kPa}$ ). Results of $\mathrm{CD}$ tests are simulated during suction equilibrium and isotropic loading stages for estimation of the mechanical parameters (Fig. 7). All the model
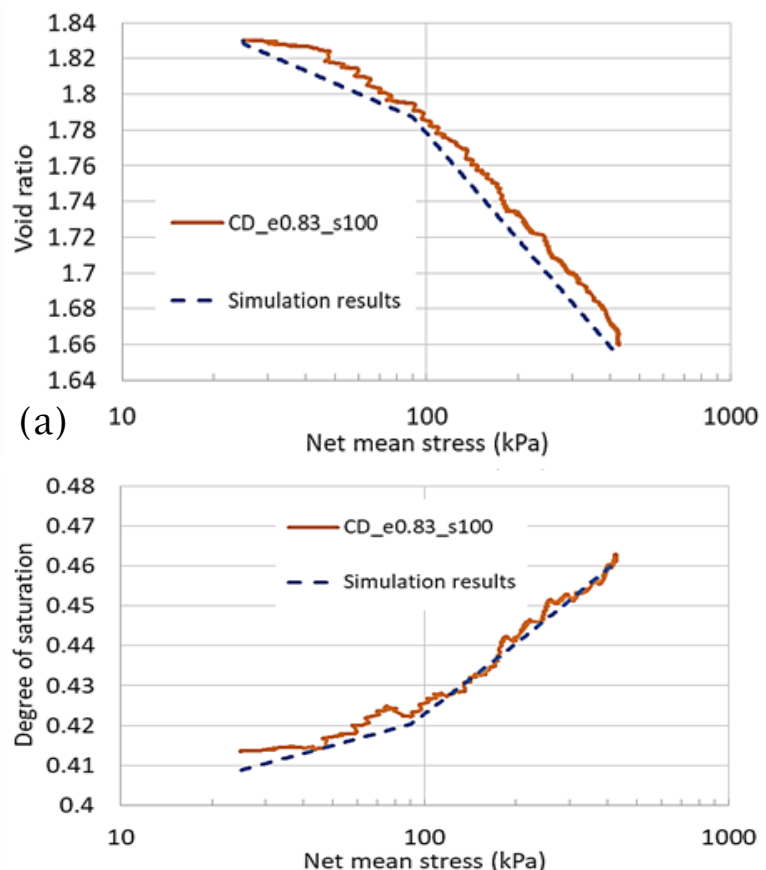

(b) 7. Calibration of model parameters from conducted experiment on Mersin silt.
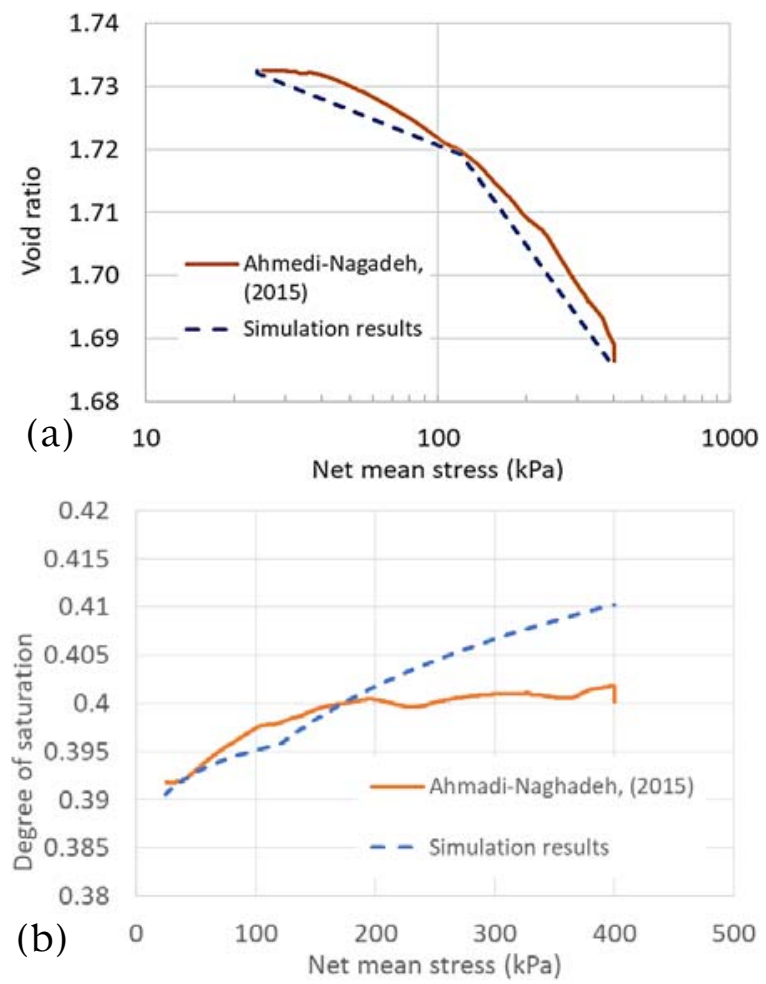

Fig. 8. Comparison of the simulation results to the experiment (Ahmadi-Naghadeh, 2015 [14]). parameters $\left(\lambda, \kappa, \kappa_{s}, k\right)$ including the van Genuchten parameters $(\mathrm{vG})$ for both drying (subscript $d$ ) and wetting (subscript $w$ ), are given in Table 1. Once the model is calibrated for the Mersin silt, the CD test by Ahmadi-Naghadeh (2015) [14] on the same soil albeit at a different initial void ratio, is simulated. While the compression behavior and the early changes in the degree of saturation are somewhat captured with the calibrated model parameters, after about $\overline{\mathrm{p}}=200 \mathrm{kPa}$ of net stress results begin to deviate yielding a difference in the degree of saturation as 0.01 at $\bar{p}=400 \mathrm{kPa}$ between the proposed model and the test (Fig. 8).

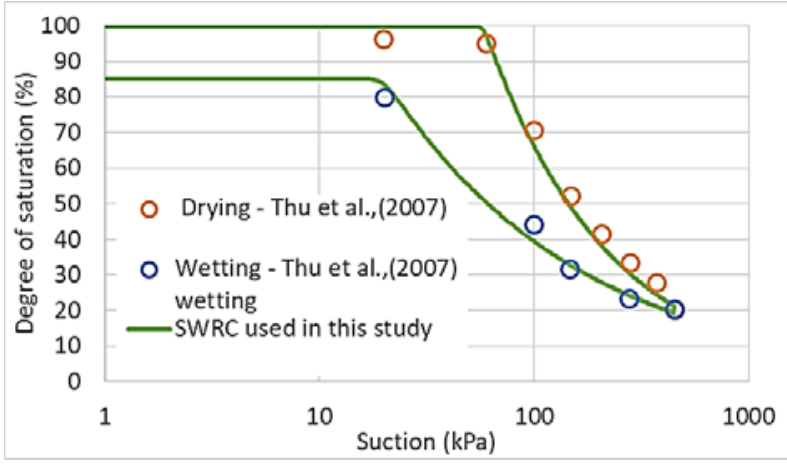

Fig. 6. The SWRC of soil in Thu et al. (2007) [15].
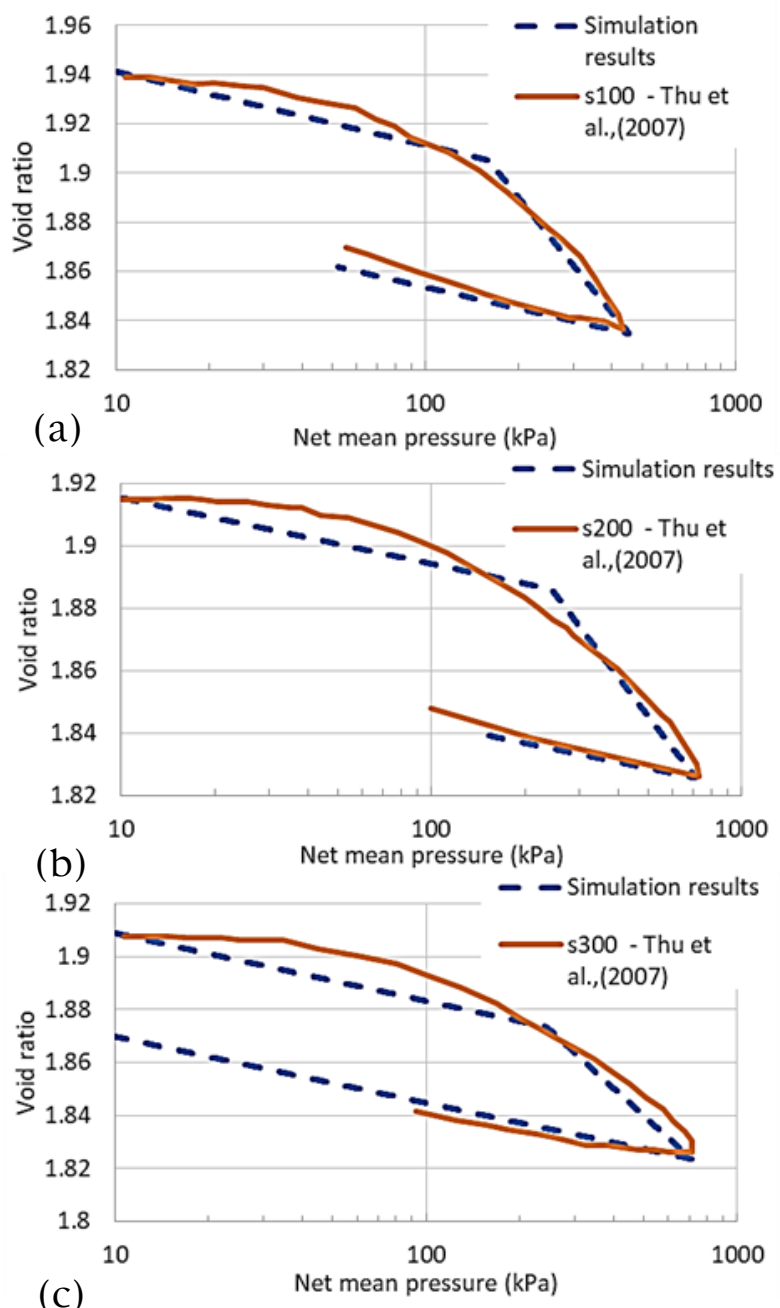

Fig. 9. Comparison comparison of simulation results to Thu et al. (2007) [15]. 
Another set of simulations is run using the experimental study of Thu et al. (2007) [15]. The study involves three isotropic loading tests performed on various constant suctions $(\mathrm{s}=100,200,300 \mathrm{kPa})$ whose results are presented in "void ratio-net mean stress" plot (Fig. 9) and the "specific volume of water-net mean stress" plot (Fig. 10). The specific volume of water is defined as:

$$
v_{w}=e S_{r}+1
$$

The simulation results of Fig. 9 capture the overall behavior of the experimental results of Thu et al. (2007) [15] where the discrepancy between the two behaviors comes mainly from the fact that the experimental data follow linear paths during loading. Nevertheless, the unloading responses match well. Comparisons between the same experiments made in terms of specific volume given in Fig. 10 confirm that the model can predict the main pattern of the change in degree of saturation caused by isotropic net stress.
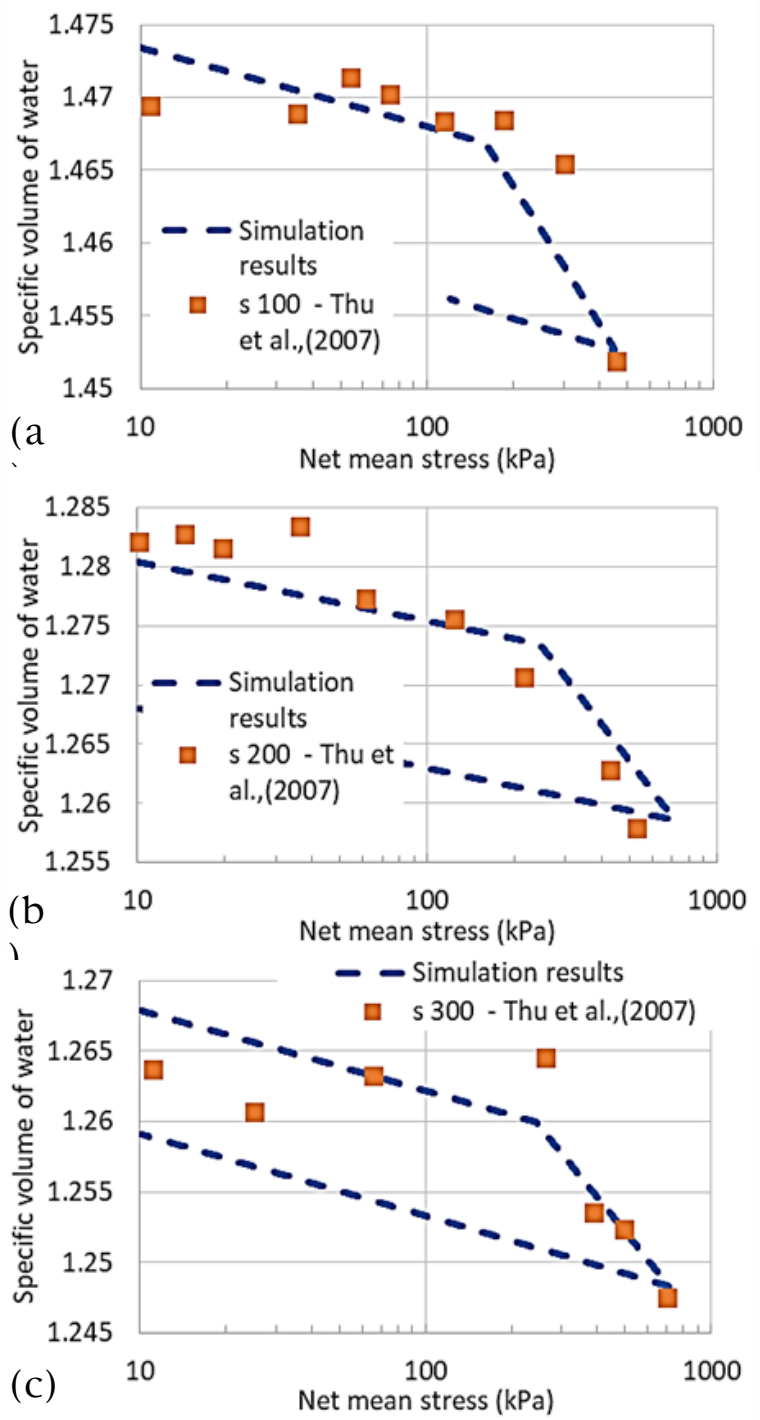

Fig. 10. Comparison comparison of simulation results to Thu et al. (2007) [15].
One of the experimental tests conducted by Raveendiraraj (2009) [16] includes a drying-wetting cycle $(\mathrm{s}=30 \rightarrow 300 \rightarrow 40 \rightarrow 200 \mathrm{kPa})$ prior to isotropic loading. The whole drying-wetting cycle in Fig 11-a occurs on scanning curves at a constant net mean stress $(10 \mathrm{kPa})$. Fig. 11-b and Fig. 11-c are the results of isotropic loading phase at constant suction $(200 \mathrm{kPa})$. Again the overall response is fairly simulated by the proposed model.
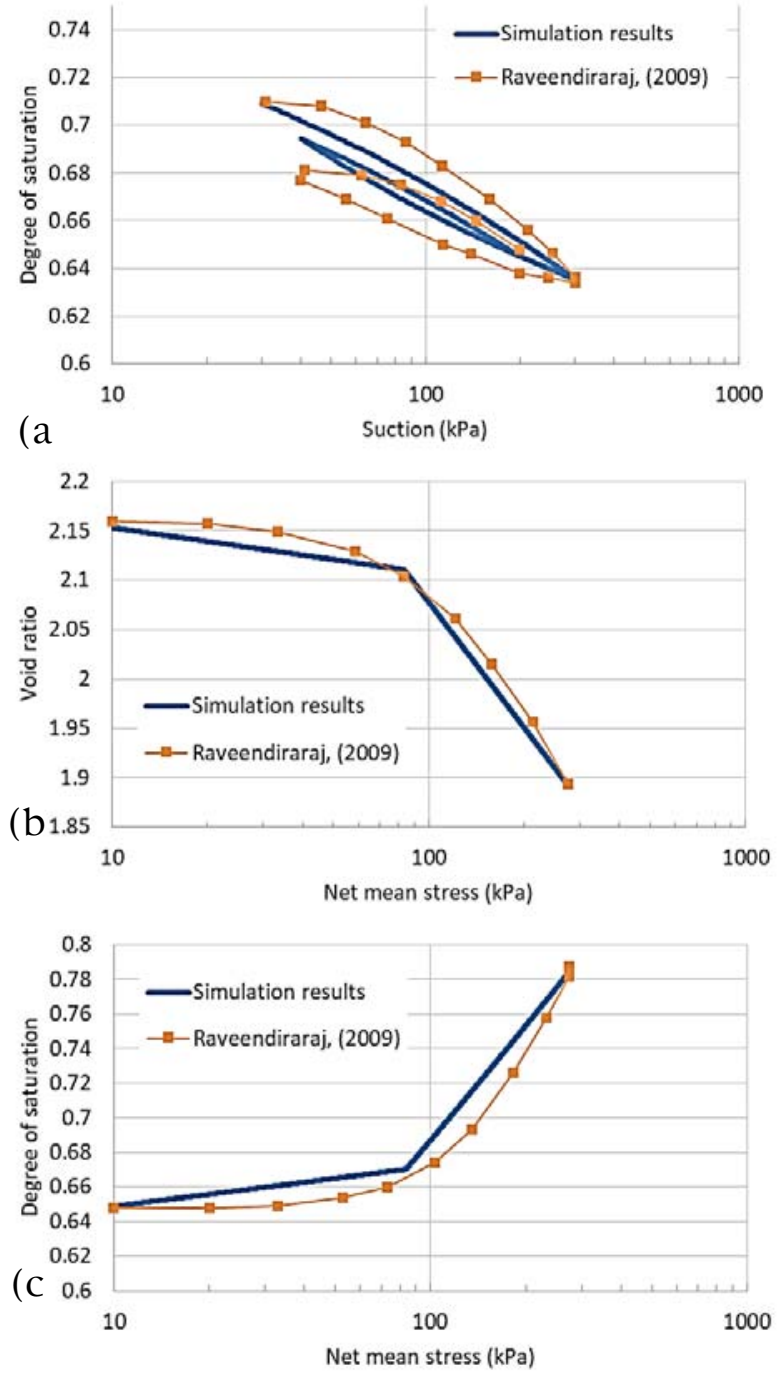

Fig. 11. Comparison of simulations to Ravendiraraj (2009) [16].

\section{Conclusion}

An unsaturated soil constitutive model, that has one-way hydromechanical coupling, while including hysteretic and scanning soil-water retention curves (SWRC), is implemented on the elastoplastic foundation of Barcelona Basic Model (BBM). The model requires BBM parameters as well as main drying and main wetting SWRCs. The model is tested with the data from the isotropic compression stages of unsaturated triaxial experiments of one performed in this study and two other from available literature. Although the non- 
linearity of actual soil behavior cannot be captured by the log-linear framework of the BBM, the proposed model delivers a simplified fit to the experimental results. Model validation in regime reversals in mechanical and hydraulic loading schemes (i.e. loadingunloading and drying-wetting-drying) establish a good basis for development of more elaborate models of shear behavior and two-way coupling that can properly model the hysteretic water retention behavior of unsaturated soils.

\section{Acknowledgements}

The authors wish to acknowledge the support provided by the Scientific and Technical Research Council of Turkey (TÜBİTAK) under project number 117M330.

\section{References}

1. E.E. Alonso, A. Gens, A. Josa. (1990). A constitutive model for partially saturated soils. Geotechnique $\quad \mathbf{4 0}: 3, \quad 405-30, \quad$ doi: 10.1680/geot.1990.40.3.405

2. A. Gens. (2010). Soil-environment interactions in geotechnical engineering. Geotechnique 60:1, 3-74, doi: 10.1680/geot.9.P.109

3. S. J. Wheeler \& V. Sivakumar. (1995). An elastoplastic critical state framework for unsaturated soil. Geotechnique 45:1, 35-53, doi: 10.1680/geot.1995.45.1.35

4. Y.J. Cui \& P. Delage. (1996). Yielding and plastic behavior of an unsaturated compacted silt. Geotechnique $\quad \mathbf{4 6}: 2, \quad 291-311$, doi: 10.1680/geot.1996.46.2.291

5. M. Sanchez, A. Gens, L. do N. Guimarães, S. Olivella. (2005). A double structure generalized plasticity model for expansive materials. Int. J. Numer. Anal. Methods Geomech. 29:8, 751-787, doi: 10.1002/nag. 434

6. A. Tarantino. (2009). A water retention model for deformable soils. Geotechnique 59:9, 751-762, doi: 10.1680/geot.7.00118

7. D. Gallipoli, A.W. Bruno, F. D’Onza, C. Mancuso. (2015). A bounding surface hysteretic water retention model for deformable soils. Geotechnique 65:10, 793-804, doi: 10.1680/jgeot.14.P.118

8. Y. Lins, Y. Zou, T. Schanz. (2007). Physical modelling of SWCC for granular materials. Theoretical and numerical unsaturated soil mechanics, Weimar, Germany, p.61-74. doi: 10.1007/3-540-69876-0_7

9. G.A. Miller, C.N. Khoury, K.K. Muraleetharan, C. Liu, T.C.G. Kibbey. (2008). Effects of soil skeleton deformations on hysteretic soil water characteristic curves: Experiments and simulations. Water Res. Res. 44:5, doi: 10.1029/2007WR00649

10. N. Lu \& M. Khorshidi. (2015). Mechanisms for Soil-Water Retention and Hysteresis at High Suction
Range. J. of Geotech. and Geoenviron. Eng. 141:8, doi: 10.1061/(ASCE)GT.1943-5606.0001325

11. M.T. van Genuchten. (1980). A closed-form equation for pre-dicting the hydraulic conductivity of unsaturated soils. Soil. Sci. Soc. Am. J. 44:5 892898.

12. M.B. Kenanoğlu \& N.K. Toker. (2018). A formulation for scanning soil-water characteristic curves. Journal of Polytechnic 21:4, 901-906. doi: 10.2339/politeknik.389619

13. M.H. Mohamed \& R.S. Sharma. (2007). Role of dynamic flow in relationships between suction head and degree of saturation. J. Geotech. Geoenviron. Eng., 133:3, 286-294, doi : 10.1061/(ASCE)10900241(2007)133:3(286)

14. R.A. Naghadeh. (2015). Hydro-mechanical behavior of unsaturated isotropically reconstituted specimens from slurry and compacted specimens. Doctoral dissertation, Middle East Technical University.

15. T. M. Thu, H. Rahardjo, E. C. Leong. (2007). Soilwater characteristic curve and consolidation behavior for a compacted silt. Canadian Geotech. J., 44:3, 266-275. doi: 10.1139/t06-114

16. A. Raveendiraraj. (2009). Coupling of mechanical behavior and water retention behavior in unsaturated soils. Doctoral dissertation, University of Glasgow. 